\title{
20 Zahnräder und Zahnradgetriebe (Grundlagen)
}

\section{1}

a) Die Gesamtübersetzung allgemein $i_{\text {ges }}=i_{1} \cdot i_{2} \cdot \ldots i_{\mathrm{n}}$

b) die Abtriebsdrehzahl aus $n_{\mathrm{ab}}=n_{\mathrm{an}} / i_{\text {ges }}$ mit $i_{\text {ges }}=i_{1} \cdot i_{2}$

c) das am Abtrieb zu erwartende Drehmoment wird gegenüber dem Antriebsmoment entsprechend der Übersetzung größer sein. Geringe Verluste werden durch den Wirkungsgrad $\eta$ berücksichtigt. Allgemein errechnet sich das Drehmoment $T$ aus der Grundgleichung $P=T \cdot 2 \cdot \pi \cdot n$ und das Abtriebsmoment aus $T_{\mathrm{ab}}=T_{\mathrm{an}} \cdot i_{\mathrm{ges}} \cdot \eta$.

\section{2}

a) Die Abtriebsdrehzahl ist vorgegeben; die Gesamtübersetzung errechnet sich aus $i_{\text {ges }}=$ $n_{\mathrm{an}} / n_{\mathrm{ab}}$

b) bei einem zweistufigen Getriebe wird die Gesamtübersetzung $i_{\text {ges }}=i_{1} \cdot i_{2}$ bzw. $i_{\text {ges }}=$ $\left(z_{2} / z_{1}\right) \cdot\left(z_{4} / z_{3}\right)$. Mit den aus der Abbildung bekannten Zähnezahlen lässt sich die Zähnezahl $z_{4}$ des Rades der zweiten Getriebestufe ermitteln aus $z_{4}=i_{\text {ges }} \cdot z_{3} /\left(z_{2} / z_{1}\right)$. Der errechnete Wert ist sinnvoll zu runden.

c) aus $P_{\mathrm{ab}}=P_{\mathrm{an}} \cdot \eta_{\mathrm{ges}} ; T_{\mathrm{ab}}=T_{\mathrm{an}} \cdot i_{\mathrm{ges}} \cdot \eta ; T=P /(2 \cdot \pi \cdot n)$ kann die Leistung ermittelt werden.

\section{3}

Allgemein errechnet sich der Gesamtwirkungsgrad aus Gl. (20.4/20-3) bzw. aus Gl. (20.5/20-4). Zu beachten sind die 3 Verzahnungsstufen, 4 Wellenlagerungen und 2 Wellendichtungen (Angaben hierzu siehe zu Gl. (20.5/20-4)). 